This item was submitted to Loughborough's Research Repository by the author.

Items in Figshare are protected by copyright, with all rights reserved, unless otherwise indicated.

\title{
UK macroeconomic volatility: Historical evidence over seven centuries
}

PLEASE CITE THE PUBLISHED VERSION

https://doi.org/10.1016/j.jpolmod.2018.04.002

PUBLISHER

Elsevier () The Society for Policy Modeling

VERSION

AM (Accepted Manuscript)

PUBLISHER STATEMENT

This paper was accepted for publication in the journal Journal of Policy Modeling and the definitive published version is available at https://doi.org/10.1016/j.jpolmod.2018.04.002.

\section{LICENCE}

CC BY-NC-ND 4.0

\section{REPOSITORY RECORD}

Plakandaras, Vasilios, Rangan Gupta, and Mark Wohar. 2018. "UK Macroeconomic Volatility: Historical Evidence over Seven Centuries”. Loughborough University. https://hdl.handle.net/2134/34990. 


\title{
An Assessment of UK Macroeconomic Volatility: Historical Evidence Using Over Seven Centuries of Data $^{\#}$
}

\author{
Vasilios Plakandaras ${ }^{*}$, Rangan Gupta ${ }^{+* *}$ and Mark E. Wohar ${ }^{* * *}$
}

*Department of Economics, Democritus University of Thrace, Greece

Email: vplakand@econ.duth.gr

** Department of Economics, University of Pretoria, South Africa.

Email: rangan.gupta@up.ac.za

${ }^{* * *}$ College of Business Administration, University of Nebraska at Omaha USA, and School of Business and Economics, Loughborough University, UK; Email:

mwohar@unomaha.edu

\begin{abstract}
Breaking ground from all previous studies, we estimate a time-varying Vector Autoregression model that examines the time-period 1270-2016 - the entire economic history of the U.K. Focusing on permanent and transitory shocks in the economy, we study the fluctuation in conditional volatilities and time-varying long-run responses of output growth and inflation. Unlike all previous studies that use time invariant linear models, our approach reveals that the pre 1600 period is a turbulent economic period of high volatility that is only repeated in the $20^{\text {th }}$ century. The repeating patterns in the conditional volatilities follow from aggregate supply shocks, while most of the inflation responses follow from aggregate demand shocks. Thus, we uncover that despite the technological growth and the various changes in the structure of the U.K. economy in the last century, the recurring patterns call for an examination of the true impact of the various policies on the economy.
\end{abstract}

Keywords: Time-Varying VAR, Macroeconomic Shocks

JEL Code: C32

\footnotetext{
\# We would like to thank four anonymous referees for many helpful comments. However, any remaining errors are solely ours.

${ }^{+}$Corresponding author.
} 


\section{Introduction}

An intriguing issue in the applied economics literature is the assessment of inflation and output volatility, given that high volatility appears during periods of high macroeconomic uncertainty and turbulence. A stylized fact in the relevant literature is that volatility is not constant over time, while the sources of volatility can be attributed to changes in the fiscal and monetary policy and to other significant political events. The majority of the extant literature investigates economic activity for the U.S. economy for the post 1900s period, while many economist limit their analysis to the post Wold War II (WWII) period.

When it comes to studying macroeconomic shocks to output, a popular selection among authors is to study the effects of permanent and transitory shocks (Bordo, 1993; Karras, 1994; Gali and Keating and Valcarcel, 2017) on the economy. Apart from the obvious reason that most statistical software packages provide such an option (in the context of Blanchard and Quah (1989)), the use of permanent and transitory shocks allows for interpretations of a structural model based on aggregate supply and demand shocks, as proposed by economic theory. Given the recent econometric advances in the construction of models with time-varying coefficients, one could assume that shocks are not time-invariant and evolve over time. We go beyond the literature that employs time-invariant coefficients on inflation and output shocks and extend this to the superior time-varying approache (see among others Barnett et al., (2014); Keating and Valcarcel (2017)).

A starting point when it comes to time-varying macroeconomic models are the seminal works of Cogley and Sargeant (2005) and Cogley et al. (2010). The authors develop structural models with time varying parameters and stochastic errors to investigate whether U.S. inflation persistence has changed in the post WWII period. They conclude that the persistence of the gap between inflation-trend inflation has increased during the 1970s and that it declined after the 1984 Great Moderation disinflation period. These findings directly account for a change in the dynamics of inflation. Belatti (2008) studies temporal changes in the U.K. inflation and output dynamics using a model with time-varying coefficients and stochastic volatility for the post WWII period. His findings suggest that the Great Inflation period that the 
U.K. economy experienced during the 1970s can be attributed to large demand shocks and to a lesser extent to supply shocks.

In a similar vein Keating and Valcarcel (2017) develop a model with timevarying parameters and stochastic volatility to examine the evolution of inflation and output volatilities for the period 1894-2015 on eight economies, including the U.S. and the U.K. The focus of their analysis is on the effects of the Great Moderation period on the global economy and more specifically on the stabilization of the economy through a drop in the volatility of prices. Their results suggest that despite the existence of a significant drop during the period 1984-2008, most of the stabilization in prices was lost in the aftermath of the 2008 recession. Moreover, the authors detect a significant drop in U.S. inflation volatility during the post WWII period, larger than the one that occurred during the Great Moderation period.

While most previous papers focus on the study of the $20^{\text {th }}$ and the $21^{\text {st }}$ century, in this paper we examine a novel dataset that spans the period 1270-2016. In this way, we attempt to uncover changes in output growth and inflation dynamics not only for the most recent period, but also for periods that have never been studied in a time varying context. Thus, the scope of this paper is to answer whether there exist significant changes in the inflation and output growth dynamics for the $U$. K. economy over time in the long-run. How volatilities have changed over time and when extremely large changes in volatility have occurred are some of the primary questions for this paper. While we are not the first to attempt such an examination, to the best of our knowledge, all previous studies that examine such an extended dataset on inflation (Clark, 2004) or output growth (Clark, 2006; Broadberry and Fouquet, 2015) use time-invariant models and approaches that fail to uncover volatility variations over time.

In order to achieve our objectives we develop a Vector Autoregression model with time-varying parameters (TVP-VAR) for the U.K. that incorporates output growth and inflation with stochastic volatility of the errors (heteroskedastic errors). Within a TVP-VAR model with stochastic volatility we do not impose the strict homoscedasticity assumption on the error structure, which better fits to the actual simultaneous relations among variables. This gain in flexibility comes at the expense of a more complicated estimation structure. The estimation of the model requires 
using Markov-Chain Monte-Carlo (MCMC) methods with Bayesian inference. We also trained a trivariate version of the model that includes additionally the interest rate of the Bank of England for a shorter time period 1700-2016, due to data availability. The empirical findings are common for the overlapping periods, so we proceed with our analysis with the bivariate model that provides an additional 400 years of data ${ }^{1}$.

Our analysis on the unconditional volatility of output growth and inflation and the response of conditional volatilities to a permanent and a transitory (nominal) output shock reveals a recurring pattern. High volatilities in the pre-1600 periods are reappearing in the early $20^{\text {th }}$ century. Following the revealed patterns in the conditional volatility, we observe higher conditional volatilities in the $20^{\text {th }}$ century relative to the $1600-1800$ period. Moreover, most of the output growth volatility could be attributed explicitly to technology shocks while inflation volatility arises from short-tempered price shocks.

The second issue that we wish to answer is which structural factors explain these changes in inflation and output growth volatilities. In doing so, we follow the typical approach in the literature (see for example, Bullard and Keating (1995), Rapach (2003) for detailed discussions) and extract responses from the model based on permanent and transitory shocks in a Blanchard and Quah (1989) type identification scheme of the impulse responses. According to the economic theory, the permanent shock on output is an aggregate supply (real) shock, while the transitory shock expresses aggregate demand (nominal) shocks. Thus, given the assumptions implied by the theory for the identification of the structural shocks to be structurally valid, we follow the approach of Blanchard and Quah (1989) -henceforth BQ- and place output growth first in the our VAR model. Our empirical findings corroborate with theory, attributing most of the output growth response to aggregate supply shocks and that of inflation to aggregate demand shocks.

In the next sections, we present the basic structure of the TVP-VAR model and the identification method of the structural shocks. Thereafter, our empirical findings and the conclusions based on our findings are discussed.

\footnotetext{
${ }^{1}$ The empirical findings of the trivariate TVP-VAR model are reported in the Appendix.
} 


\section{Methodological issues}

\subsection{The time-varying VAR model}

Our work is motivated by Cogley and Sargent (2005) and Canova and Gambetti (2010) who train a TVP-VAR model with Bayesian methods to allow for time-varying VAR coefficients with stochastic volatility of the innovations. We consider a reduced VAR model:

$$
\theta_{t}(L) x_{t}=e_{t}
$$

with $x_{t}=\left\{\Delta y_{t}, \Delta p_{t}\right\}$ representing an n-vector of endogenous variables (namely output growth $(\Delta y)$ and inflation $\left(\Delta p_{t}=\pi\right)$, at each point of time $t$, each $\theta_{j t}$ in $\theta_{t}(L)=I-\theta_{1 t} L-\cdots-\theta_{1 t} L^{1}$ is a matrix of time-varying coefficients and $e_{t}$ is a vector of zero mean VAR errors with a time-varying covariance matrix $\mathrm{R}_{t}$. The coefficients in (1) evolve according to:

$$
\theta_{t}=\theta_{t-1}+u_{t}
$$

with $\theta_{t}$ denoting the vector that stacks all parameters in $\theta_{t}(L)$ and $u_{t}$ is a Gaussian white noise process with zero mean and constant covariance matrix Q, independent of $\varepsilon_{t}$ at all leads and lags. We model the time variations of innovations $\mathrm{R}_{t}=\mathrm{E}\left(e_{t} e_{t}^{\prime}\right)=$ $F_{t} D_{t} F_{t}^{\prime}$, where $F_{t}$ is a lower diagonal matrix with ones in the main diagonal and $D_{t}$ a diagonal matrix. In order to provide flexibility to our model we drop the typical homoscedasticity assumption and allow for the existence of stochastic volatility on the VAR errors. In order to achieve this we compute the covariance matrix $\mathrm{R}_{t}$ as follows:

Let's assume that $\gamma_{t}$ is a vector containing all the elements of $F_{t}^{-1}$ below the diagonal, stacked by rows. Then to include stochastic volatility, $\gamma_{t}$ follows (3):

$$
\gamma_{t}=\gamma_{t-1}+\zeta_{t}
$$

In a similar vein, $\sigma_{t}$ is a vector of diagonal elements of $D_{t}$ stacked by rows and follows (4): 


$$
\log \sigma_{t}=\log \sigma_{t-1}+\xi_{t}
$$

where $\zeta_{t}$ and $\xi_{t}$ are Gaussian white noise processes with zero mean and (constant) covariance matrices $\Psi$ and $\Xi$, respectively. In order to be able to estimate our model we make a few modest assumptions: a) we assume that $\Psi$ has a block diagonal structure, i.e. all covariances between coefficients belonging to different equations are zero, b) that $\Xi$ is diagonal and c) that $\zeta_{t}, \xi_{t}$ and $u_{t}$ are all mutually independent.

Following the typical structural literature related to VARs, the vector of VAR innovations $e_{t}$ is a (time-varying) linear transformation of the underlying "structural" shocks $\varepsilon_{t}=\left\{\varepsilon_{t}^{y}, \varepsilon_{t}^{\pi}\right\}^{\prime}$. The model satisfies $E\left(\varepsilon_{t} \varepsilon_{t}^{\prime}\right)=I$, with $\varepsilon_{t}^{y}$ representing a permanent (real / technology) shock and $\varepsilon_{t}^{\pi}$ an transitory (nominal / price) shock on output growth and a corresponding permanent (technology) shock of output on inflation and a temporary (idiosyncratic) inflation shock. We state that $e_{t}=\varphi_{t} \varepsilon_{t}$, where $\varphi_{t}$ is a nonsingular matrix that satisfies $\varphi_{t} \varphi_{t}^{\prime}=R_{t}$. Given this normalization scheme, changes in the contributions of different structural shocks to the volatility of innovations to variables are captured by changes in $\varphi_{t}$. Let the companion form of (1) be:

$$
X_{t}=\Theta_{t} X_{t-1}+H e_{t}
$$

where $X_{t}=\left(x_{t}^{\prime}, x_{t-1}^{\prime}, \ldots, x_{t-l+1}^{\prime}\right)^{\prime}, H=(I, 0, \ldots, 0)^{\prime}$ and $\Theta_{t}$ is the companion-form matrix derived from the autoregressive coefficients of (1). A local projection of (5) yields:

$$
\frac{\partial x_{t+k}}{\partial e_{t}}=s_{n, n}\left(\Theta_{t}^{k}\right) \quad \forall t, k=0,1,2, \ldots
$$

where $s_{n, n}(\cdot)$ is the selector function that selects the $n$ rows and columns of a matrix. The application of the chain rule yields the following impulse response at an arbitrary $k$-th horizon:

$$
\frac{\partial x_{t+k}}{\partial \varepsilon_{t}}=\frac{\partial x_{t+k}}{\partial e_{t}} \frac{\partial e_{t}}{\partial \varepsilon_{t}}=s_{n, n}\left(\Theta_{t}^{k}\right) \varphi_{t} \quad \forall t, k=0,1,2, \ldots
$$

We are interested in the identification of level responses and thus of the 
cumulative responses to each variable. We define $\bar{\Theta}_{t}^{k}=\sum_{j=0}^{k} \Theta_{t}^{j}$ where the level response of each variable to each shock at $k$ periods is the accumulated response of the differenced series from period zero to period $k \cdot M_{t, k}=\sum_{j=0}^{k} s_{n, n}\left(\Theta_{t}^{j}\right) \varphi_{t}$. From the properties of the selector function we obtain $M_{t, k}=s_{n, n}\left(\bar{\Theta}_{t}^{k}\right) \varphi_{t}$. Letting $k \rightarrow \infty$ defines the time-varying matrix of long-run cumulative multipliers that indicate the long-run effect of each shock on the variable of interest.

As stated in the introduction section, our identification method of structural shocks follows a BQ type with long-run restrictions on the innovations in order to decompose the responses into permanent and transitory shocks. The identification of the structural shocks is based on well-documented macroeconomic hypotheses. First, according to the long-run neutrality of money, an increase or decrease in money supply cannot affect (real) output. Moreover, according to the natural rate hypothesis, the single source of non-stationarity in real output stems from disturbances to aggregate supply and thus from technological advancements. Thus, we restrict exogenous changes of an inflationary shock to have no long-run effect on output, placing inflation second in the VAR. Thus, for the definition of $M_{t, k}$ we use:

$$
M_{t} M_{t}^{\prime}=s_{n, n}\left(\bar{\Theta}_{t}^{\infty}\right) R_{t}\left(s_{n, n}\left(\bar{\Theta}_{t}^{\infty}\right)\right)^{\prime}
$$

with $M_{t}$ obtained from the Cholesky decomposition of (8). Given $M_{t}$ we can solve for $\varphi_{t}$ and obtain the structural impulse responses of each shock according to the ordering $\varepsilon_{t}=\left\{\varepsilon_{t}^{y}, \varepsilon_{t}^{\pi}\right\}^{\prime}$ :

$$
\frac{\partial x_{t+k}}{\partial \varepsilon_{t}}=s_{n, n}\left(\Theta_{t}^{k}\right)\left(s_{n, n}\left(\bar{\Theta}_{t}^{\infty}\right)\right)^{-1} M_{t} \quad \forall t, k=0,1,2, \ldots
$$

Based on recursive substitution on (7) each variable can be written as a timevarying moving representation driven by the underlying structural disturbances. If $x_{i, t}$ represents a distributed lag process for each variable contingent of shock $\mathrm{j}$, we have:

$$
x_{i, t}=\mu_{t}^{i}+\sum_{k=0}^{\infty}\left[\bar{N}_{t, k}\right]_{i, j} \varepsilon_{t-k}^{j}
$$

for $i=\left\{\Delta y_{t}, \pi_{t}\right\}, \varepsilon_{t-k}^{j}=\left\{\varepsilon_{t-k}^{y}, \varepsilon_{t-k}^{\pi}\right\}$ and $\bar{N}_{t, k}=s_{n, n}\left(\Theta_{t}^{k}\right)$. From (10) we see that the 
time-varying unconditional variance of $x_{i, t}$ is decomposed into the contribution of each shock to the variance of each variable according to the following:

$$
\operatorname{var}_{t}\left(x_{i, t}\right)=\sum_{k=0}^{\infty}\left[s_{n, n}\left(\Theta_{t}^{k}\right) \varphi_{t}\right]_{i, j}^{2}
$$

and the time varying covariance of $x_{i, t}$ and $x_{q, t}$ conditional on each shock $\mathrm{j}$ is given by:

$$
\operatorname{covar}_{t}\left(x_{i, t}, x_{q, t}\right)=\sum_{k=0}^{\infty}\left[s_{n, n}\left(\Theta_{t}^{k}\right) \theta_{t}(1) M_{t}\right]_{i, j}\left[s_{n, n}\left(\Theta_{t}^{k}\right) \theta_{t}(1) M_{t}\right]_{q, j}
$$

Time-varying unconditional and conditional correlations are given tractably from (11) and (12).

\subsection{Bayesian Estimation}

Our estimation procedure draws directly from Canova and Gambetti (2010).

\section{Priors}

Let $z^{T}$ dente the sequence of $z$ 's up to time T. Let $\gamma$ be the vector containing the non-zero elements of $F^{-1}$ that are different from one and are stacked in rows and $\Xi$ a vector including all the $\Xi_{i}$. The transition density is assumed to be

$$
\begin{gathered}
p\left(\theta_{t} \mid \theta_{t-1}, \Omega\right) \propto I\left(\theta_{t}\right) f\left(\theta_{t} \mid \theta_{t-1}, \Omega\right) \\
p\left(\theta_{t} \mid \theta_{t-1}, \Omega\right)=N\left(\theta_{t-1}, \Omega\right)
\end{gathered}
$$

where $I\left(\theta_{t}\right)$ is an indicator function selecting non-explosive draws of $\theta_{t}$ for $y_{t}$. We assume the hyperparameters and the initial states are independent so that the joint prior is simply the product of the marginal densities. Following Cogley and Sargent (2005) we assume:

$$
\begin{array}{r}
P\left(\theta_{0}\right) \propto I\left(\theta_{0}\right) N(\bar{\theta}, \bar{P}) \\
P(\Omega)=\operatorname{IW}\left(\bar{\Omega}^{-1}, T_{0}\right)
\end{array}
$$




$$
\begin{gathered}
P\left(\log \sigma i_{0}\right)=\mathrm{N}\left(\log \bar{\sigma}_{i}, 10\right) \\
P(\gamma)=\mathrm{N}\left(0,10000 \times I_{4}\right) \\
P\left(\Xi_{i}\right)=\operatorname{IG}\left(\frac{0.01^{2}}{2}, \frac{1}{2}\right)
\end{gathered}
$$

with $\bar{\theta}, \bar{P}$ being OLS estimates of the VAR coefficients and their variances obtained with the initial sample, $\bar{\Omega}=\lambda \overline{\mathrm{P}}, T_{0}$ is the number of observations in the initial sample (40 observations), $\bar{\sigma}_{i}$ is the estimate of the variance of the residual in equation $i$ obtained using the initial sample. The hyperparameter $\lambda$ is set to 0.0005 for all parameters except for the constant terms of output growth, inflation and interest rate. For these constants, it is set to 0.001 .

\section{Posteriors}

To draw realizations from the posterior density we use the Gibbs sampler. Each iteration is composed of four steps and, under regularity conditions and after a burn-in period, iterations on these steps produce draws from the joint density.

\section{- $\quad \underline{\text { Step 1: } p\left(\theta^{T} \mid y^{T}, \gamma, \sigma^{T}, \Xi, \Omega\right)}$}

Conditional on $\left(\theta^{T} \mid y^{T}, \gamma, \sigma^{T}, \Xi, \Omega\right)$ the unrestricted posterior of the states is normal. To draw from the conditional posterior we employ the algorithm of Carter and Kohn (1994). The conditional mean and variance of the terminal state $\theta^{T}$ is computed using standard Kalman filter recursions while for all the other states the following backward recursions are employed:

$$
\begin{gathered}
\theta_{t \mid t-1}=\theta_{t \mid t}+P_{t \mid t} P_{t \mid t}{ }^{-1}\left(\theta_{t+1}-\theta_{t \mid t}\right) \\
P_{t \mid t-1}=P_{t \mid t}-P_{t \mid t} P_{t+1 \mid t}{ }^{-1} P_{t \mid t}
\end{gathered}
$$

given $p\left(\theta_{t} \mid \theta_{t+1}, y^{T}, \gamma, \sigma^{T}, \Xi, \Omega\right) \sim N\left(\theta_{t \mid t+1}, P_{t \mid t+1}\right)$

\section{- Step 2: $p\left(\gamma \mid y^{T}, \theta^{T}, \sigma^{T}, \Xi, \Omega\right)$}

Given that $\sigma^{T}$ and $y^{T}$ are known $\varepsilon_{t}$ is known and since $u_{t}$ is a standard Gaussian 
white noise, we have $D_{t}^{-1 / 2} F^{-1} \varepsilon_{t}=u_{t}$ or $D_{t}^{-1 / 2} \varepsilon_{t}=D_{t}^{-1 / 2}\left(F^{-1}-I\right) \varepsilon_{t}+u_{t}$. We can rewrite the $i$ th equation as $z_{i t}=-w_{i t} \gamma_{i}+u_{i t}$ where $z_{i t}=\varepsilon_{i t} / \sqrt{\sigma_{i t}}, w_{i t}=$ $\left[\varepsilon_{1 t} / \sqrt{\sigma_{1 t}}, \ldots, \varepsilon_{i-1, t} / \sqrt{\sigma_{i-1, t}}\right]$ and $\gamma_{i}$ is the column vector formed by the non-zero elements of the ith row of $F^{-1}-I$. Given the normal prior, the posterior is $\gamma_{i}=$ $N\left(F_{1, i}, V_{1, i}\right)$ where $F_{1, i}=V_{0, i}\left(V_{0, i}^{-1} \gamma_{0, i}+w_{i}^{\prime} z_{i}\right)$ and $V_{1, i}=\left(V_{0, i}^{-1}+w_{i}^{\prime} w_{i}\right)$ with $V_{0, i}$ and $\gamma_{0, i}$ the prior variance and mean, respectively. Drawing for $i=2,3,4$ we obtain a draw for $\gamma$.

- $\quad$ Step 3: $p\left(\sigma^{T} \mid y^{T}, \theta^{T}, \gamma, \Xi, \Omega\right)$

The elements of $\sigma^{T}$ are drawn according to Cogley and Sargent (2005) (see Appendix B.2.5 of their work for details).

- Step 4: $p\left(\Xi_{i} \mid y^{T}, \theta^{T}, \gamma, \sigma^{T}, \Omega\right), p\left(\Omega \mid y^{T}, \theta^{T}, \gamma, \sigma^{T}, \Xi\right)$

Conditional on $y^{T}, \theta^{T}, \gamma, \sigma^{T}$ and under conjugate priors, all the remaining hyperparameters, can be sampled in a standard way from Inverted Wishart and Inverted Gamma densities. We perform 20000 repetitions, discard the first 5000 draws and keep one every 10 of the remaining draws for inference to break the autocorrelation of the draws.

\section{Data and Empirical Results}

\subsection{The Data}

We compile a dataset of annual time series for the U.K. of real Gross Domestic Product (y) and the GDP deflator spanning the period of 1270-2016. Both series are from the database called "A millennium of macroeconomic data", as maintained by the Bank of England. ${ }^{2}$ Given that prior to 1801 there is no U.K., data before this period correspond to that of Great Britain or England as coded by the

2 The data is available for download http://www.bankofengland.co.uk/research/Pages/datasets/default.aspx\#threecenturies. Note that, we also estimated a trivariate model which also included the interest rate measure (the bank rate), which in turn, is also obtained from the same data source as real GDP and the GDP deflator. The results from the trivariate TVP-VAR model are reported in an extended version of the paper available at: https://ideas.repec.org/p/pre/wpaper/201779.html. 
Central Bank of England. We transform both series to logarithms. Descriptive statistics are presented in Table 1.

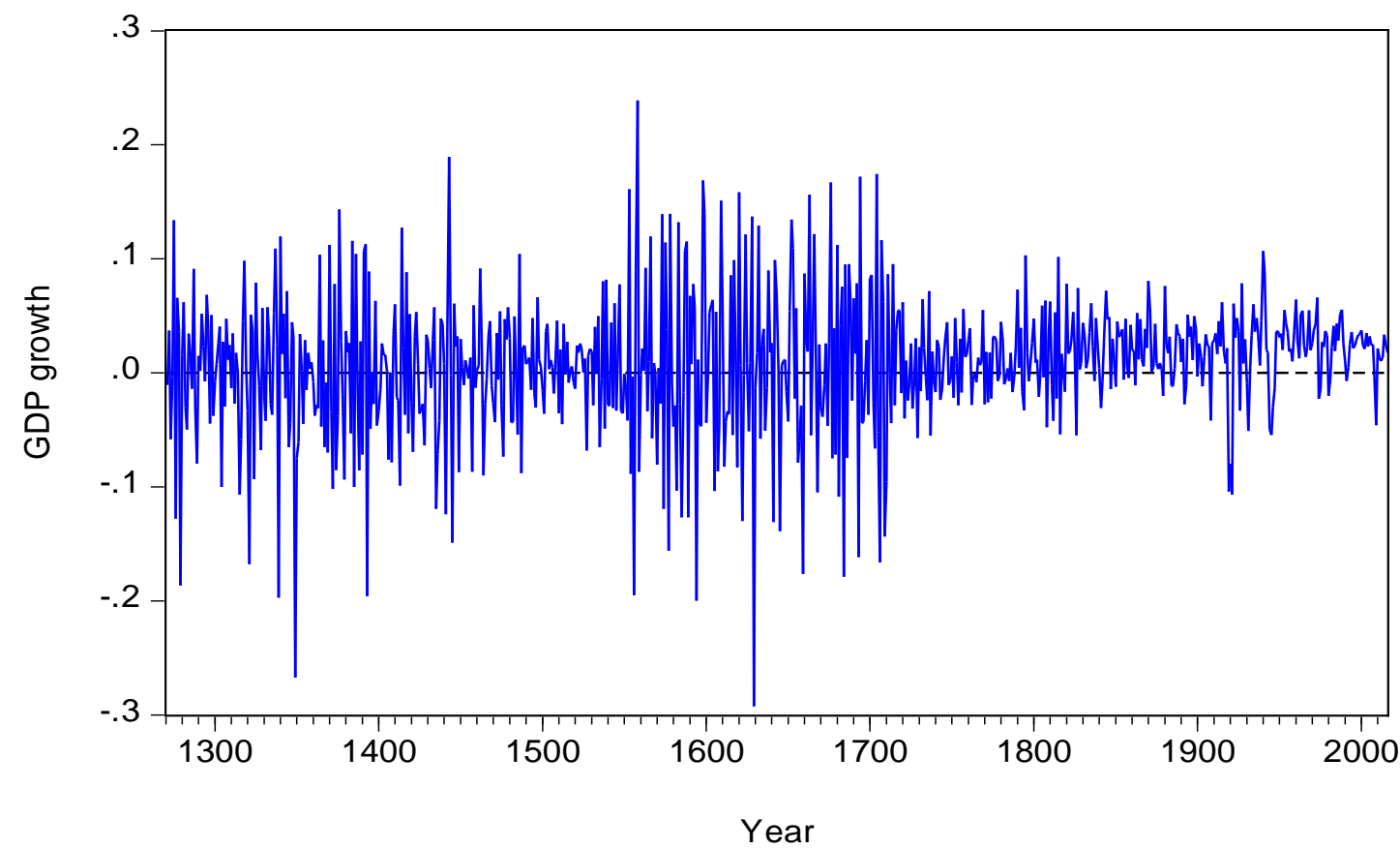

Figure 1: Logarithmic Real output growth series for the U.K.

\begin{tabular}{|c|c|c|c|c|c|c|c|c|c|}
\hline \multicolumn{10}{|c|}{ Table 1: Descriptive Statistics } \\
\hline & Mean & $\begin{array}{l}\text { Standard } \\
\text { Deviation }\end{array}$ & Skewness & Kurtosis & $\begin{array}{c}\text { Jarque } \\
\text { Bera } \\
\text { (1987) }\end{array}$ & \multicolumn{2}{|c|}{$\begin{array}{l}\text { Bai-Perron (1998) } \\
\text { multiple break test }\end{array}$} & \multirow{2}{*}{$\begin{array}{c}\text { Enders and } \\
\text { Lee (2012) } \\
\text { unit root } \\
\text { test } \\
\text { (LM } \\
\text { values) } \\
\end{array}$} & \multirow[t]{2}{*}{ Decision } \\
\hline & & & & & & $\begin{array}{l}\text { Schwarz } \\
\text { Criterion }\end{array}$ & $\begin{array}{c}\text { Liu-Wu- } \\
\text { Zidek (1997) } \\
\text { Criterion } \\
\end{array}$ & & \\
\hline \multirow{4}{*}{$\begin{array}{c}\text { GDP } \\
\text { GDP } \\
\text { deflator } \\
\Delta \text { GDP } \\
\Delta \text { GDP } \\
\text { deflator }\end{array}$} & 108059.8 & 284872.3 & 3.60 & 16.01 & $6876^{*}$ & $17.53(0)$ & $17.56(0)$ & -0.82 & $\mathrm{I}(1)$ \\
\hline & 4.21 & 15.28 & 4.60 & 23.60 & $15842 *$ & $-2.14(1)$ & $-2.08(1)$ & $-17.83 *$ & $\mathrm{I}(0)$ \\
\hline & 2236.68 & 8568.83 & 2.19 & 20.11 & 9698* & $17.50(1)$ & $17.57(1)$ & -0.57 & $\mathrm{I}(1)$ \\
\hline & 0.13 & 0.53 & 4.78 & 28.12 & $22464 *$ & $-3.36(1)$ & $-3.32(0)$ & $-7.43^{*}$ & $\mathrm{I}(0)$ \\
\hline
\end{tabular}

Note: * denotes rejection of the null hypothesis at the $5 \%$ level of significance. The null hypothesis of the Jarque -Bera (1987) test is that the series comes from the family of normal distributions. The null hypothesis of the Enders and Lee (2012) unit root test is that the series exhibits a unit root. Number in parenthesis in the Bai-Perron (1998) test denote the number of detected structural breaks in the series.

As we observe from Table 1, according to the Bai-Perron (1998) multiple breaks test, the GDP deflator series exhibits one structural break, based on both the Schwarz and the Liu-Wu-Zidek (LWZ) criterion (Liu et al., 1997), while we do not detect a structural break for the GDP series. The existence of a structural break 
renders common unit root tests such as the augmented Dickey-Fuller (Dickey and Fuller, 1981), the Phillips-Perron (Phillips and Perron, 1988) or the KwiatkowskiPhillips-Schmidt-Shin test (Kwiatkowski et al., 1992) invalid. Thus, we apply the recently proposed unit root test of Enders and Lee (2012).

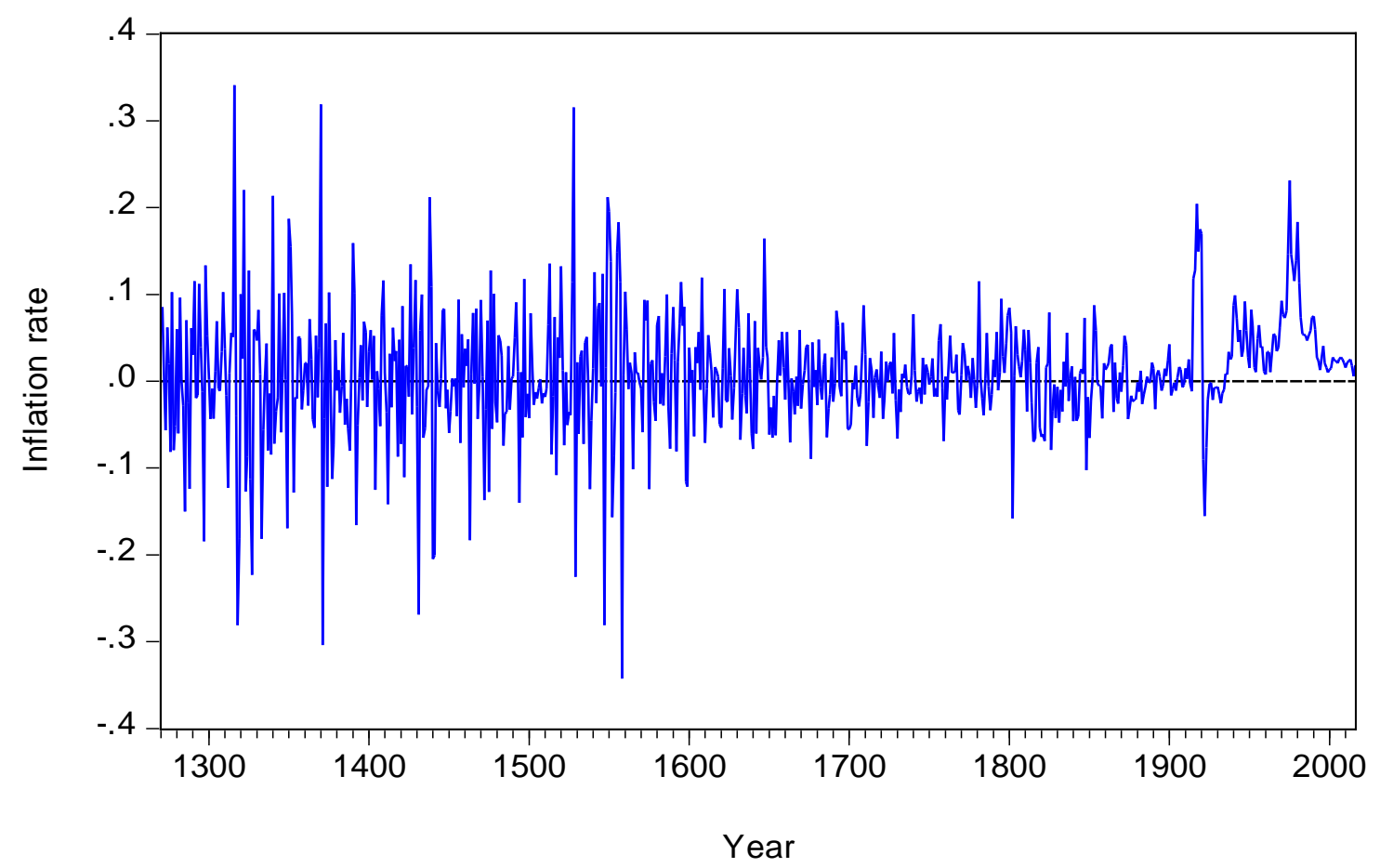

Figure 2: Inflation series for the U.K.

The Enders and Lee (2012) test approximates the series with low frequency components of the Fourier expansion without the need to define the points of the breaks. Moreover, the test is able to capture unit root processes in the presence of multiple linear and nonlinear forms of structural breaks. Following Enders and Lee (2012) we use a small number of frequency components to avoid over-fitting the series and allow the evolution of the nonlinear trend to be gradual. While both series are non-stationary in levels, they are stationary in first differences. We continue our analysis based on the output growth (differenced logarithmic GDP series) and the inflation rate (differenced logarithmic GDP deflator). The two series are depicted in Figures 1 and 2, respectively.

\subsection{Empirical findings}

An initial step when training a VAR model is to test whether one should include an error correction term in the VAR or not, making the model a Vector Error 
Correction Model (VECM). Given that both variables (real GDP and GDP deflator) are non-stationary in the levels, the initial assumption for a VECM is fulfilled. The Johansen (1991) cointegration test indicates the existence of one cointegrating vector for the entire sample (Table 2). Given that the type of analyses, for instance impulse response functions, that we aim to present, is not yet available in a time-varying VECM, we continue to focus on the TVP-VAR and compare our results with a structural VECM (SVECM) that we use as the benchmark model. ${ }^{3}$ We also fix the lag length of all models at two based on the SIC criterion applied to a Bayesian VAR with constant parameters over time. The VECM is of the same lag order as the TVP-VAR for comparison reasons ${ }^{4}$.

\begin{tabular}{cccc}
\hline \multicolumn{4}{c}{ Table 2: Cointegration test results } \\
\hline \multicolumn{4}{c}{ Panel A } \\
\hline Unrestricted Cointegration Rank Test (Trace) \\
\hline Hypothesized & Trace & 0.05 \\
No. of CE(s) & Eigenvalue & Statistic & Critical Value \\
\hline None & 0.09 & 68.00 & $15.45^{*}$ \\
At most 1 & 0.00 & 0.58 & 3.84 \\
\hline \multicolumn{4}{c}{ Panel B } \\
\hline Unrestricted Cointegration Rank Test (Maximum Eigenvalue) \\
\hline Hypothesized & Max-Eigen & 0.05 \\
No. of CE(s) & Eigenvalue & Statistic & Critical Value \\
\hline None * & 0.09 & 67.42 & $14.27^{*}$ \\
At most 1 & 0.00 & 0.58 & 3.84 \\
\hline
\end{tabular}

Note: * denotes the rejection of the null hypothesis about the number of cointegrating relationships at $5 \%$ level of significance.

\subsubsection{Output volatilities}

We now turn on the conditional and unconditional standard deviations of the output growth and inflation. In Figure 3 we show the time-varying standard deviations of output growth and inflation with the continuous (blue) and the dotted (red) line, respectively. We also mark some dates of economic importance for the U.K.:

a) 1348-the Black Death that wiped a significant part of the population,

b) 1558-the start of the Elizabethan era, a gold era for the English history,

\footnotetext{
${ }^{3}$ However note that using the test of Bierens and Martins (2010) of time-varying cointegration, we were able to reject the null of constant parameter cointegration in favour of time-varying cointegration. Complete details of these results are available upon request from the authors.

${ }^{4}$ Lag order selection criteria and the VECM model structure are available upon request by the authors.
} 
c) 1815-that marked the end of the Napoleonic wars,

d) 1914-World War I,

e) 1945-World War II,

f) 1973-the end of the Bretton Woods system and the insertion of U.K. to the European Union,

g) 1984-the miners' strike that caused significant changes to the way the economy was structured,

h) 1992-the exit of the pound from the Exchange Rate Mechanism (ERM) and the start of the Great Moderation period and,

i) 2008-the global financial crisis.

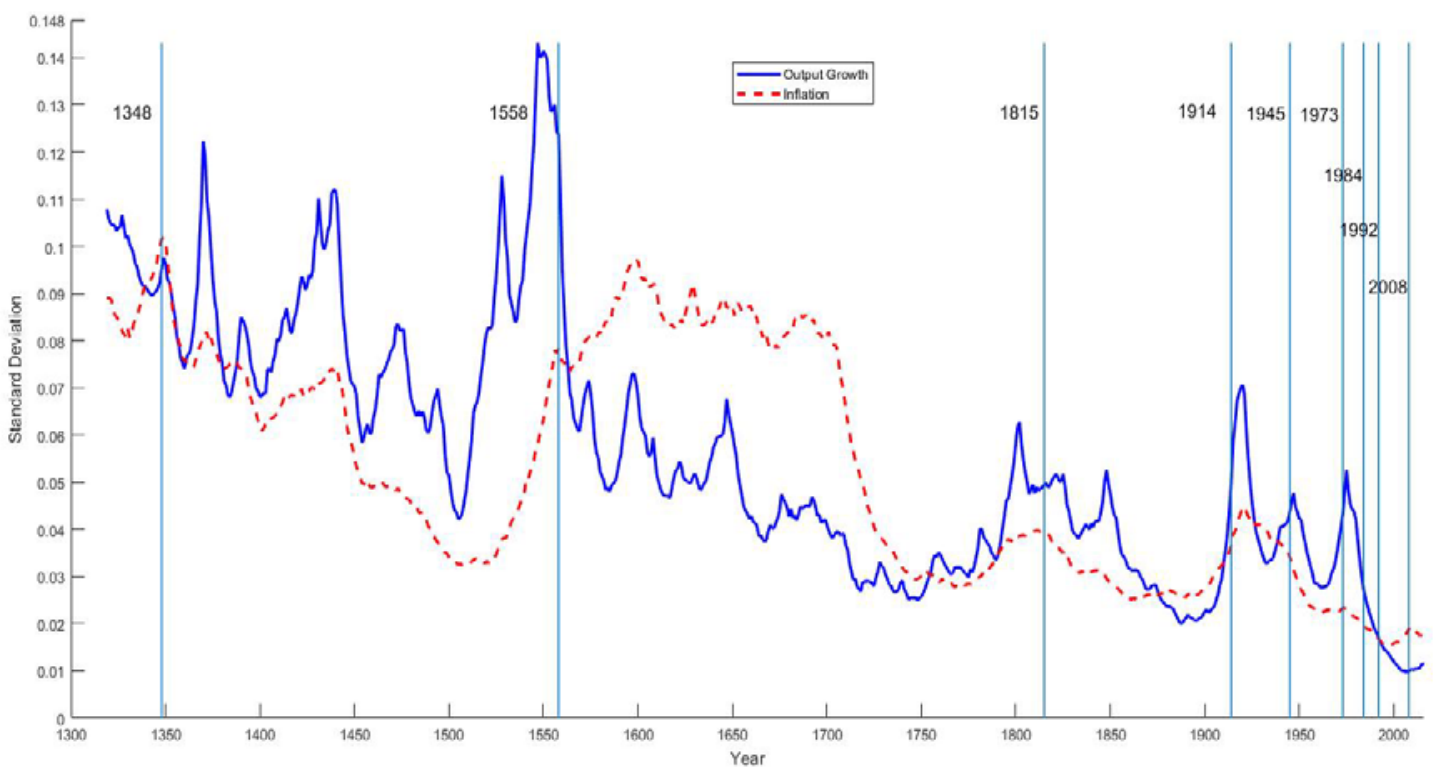

Figure 3: Time-varying standard deviations.

Of course, this list is by no means exhaustive and one could also add more dates. Nevertheless, these dates undoubtedly mark significant political and economic events for England and the later U.K., that are reflected upon the output growth and inflation volatilities. Up to 1558 the output growth exhibits high standard deviations that are peaked right before the start of the Tudors reign. In the $16^{\text {th }}$ and $17^{\text {th }}$ century, the economic growth seems to stabilize with a slight downward trend because of the tranquil economic environment and the role of England as the largest global economy with many overseas conquests. In the dawn of the $18^{\text {th }}$ century, France questions this role and this fact creates economic turbulence that is obvious in the volatility of the economic activity. With the end of the Napoleonic Wars at the Waterloo at 1815, the 
economy stabilizes again and we observe a downward trend, reaching to its lowest historical value (up to that point) at the beginning of the $19^{\text {th }}$ century. The two world wars and the dissolution of the fixed exchange rate system at 1973 are the main drivers of volatility increases in the $20^{\text {th }}$ century, while after that point and until the 2008 financial crisis we observe a steady decline in volatility reaching to the overall lowest historical point. In total, fluctuations in the economic growth rate before the $20^{\text {th }}$ century are larger in size and of greater duration.

In Panel A of Table 3 we report the median posterior volatility of output growth and in panel $\mathrm{B}$ the corresponding inflation volatility values. The boundaries for these periods are marked by the dates of the aforementioned list. This table facilitates a quantitative comparison of volatility between the various economic periods, along with the year of the extreme value in each period and the $16 \%$ and $84 \%$ confidence intervals of local peaks and troughs. We also report the volatility spread from the lowest to the highest value for each period and the percentage change in volatility between two succeeding peaks. Given the Bayesian approximation of our models, in table 3 we also report the $16 \%-84 \%$ posterior credible intervals in order to test whether the lower bound of the peak (16\%) is higher than the higher bound of the trough (84\%). We mark these cases as statistically significant, as the entire distributions do not overlap. When the lower bound on the peak exceeds the upper bound on the trough, we interpret that as evidence of a statistically significant reduction in the standard deviation.

The output growth volatility peaks follow a declining trend as we move in time from 0.143 standard deviations at 1547 to 0.124 at $1558,0.048$ at 1947,0027 at 1984 and 0.012 at 2015. The same pattern unveils for the local troughs of each period. The only exception to this rule is the 1914-1945 period, an era that is characterized by two world wars of extreme force that influenced significantly the economic activity, increasing economic and political uncertainty. Reductions in volatility are statistically significant up to 1984, while after that point the distributions of peaks and troughs overlap. This fact should be attributed to the small arithmetic magnitude of the values and not to the non-existence of a reduction. Thus, we could state that in the post 1984 period the output growth volatility is very small and that the highest reduce in volatility in the $20^{\text {th }}$ century is observed in the period $1945-1973$, where volatility 
almost halved. The same patterns also appear on inflation volatility. Most of the fluctuations in inflation rates are observed in the "earlier” periods of our sample and up to 1815. From that point on inflation volatility is small and declining, implying a steady decline of inflation rates that it gets almost steady after the 1973. Reductions in inflation volatility are statistically significant between all periods. Overall, the period with the highest reductions in the volatility of output growth and inflation is the period 1815-1914 that is characterized by the predominance of U.K. as a global economic power, with intense trade relationships and little political turbulence. The effective fiscal and monetary policies lead to a significant reduction in the volatility of either variable during the $20^{\text {th }}$ century. Interestingly, we do not observe a stabilization during the "golden” English period of 1558-1815, as stated by Clark (2004), and Broadberry and Fouquet (2015).

In Figure 4 we depict the conditional standard deviations of the output growth rate conditioned on a permanent and a transitory shock following a long-run (BQtype) identification scheme achieved by equation (11). As we observe, most of the variability in output growth could be attributed to permanent (real) output shocks that reflect aggregate supply side fluctuations. Transitory (demand side) shocks are most apparent for the early period of our sample indicating exogenous influences other than technology shocks in output growth. A small and temporal influence of the transitory (nominal) shocks are also apparent during the two world wars and the 1973 period, but in all other time frames the effect of nominal shocks are very small. In figure 5 we depict the decomposition of inflation to permanent and transitory shocks in output growth. In general, transitory shocks map inflation volatility very closely, while permanent (real) shocks influence inflation only during the periods of higher volatility (1348-1558 and 1914-1945). 


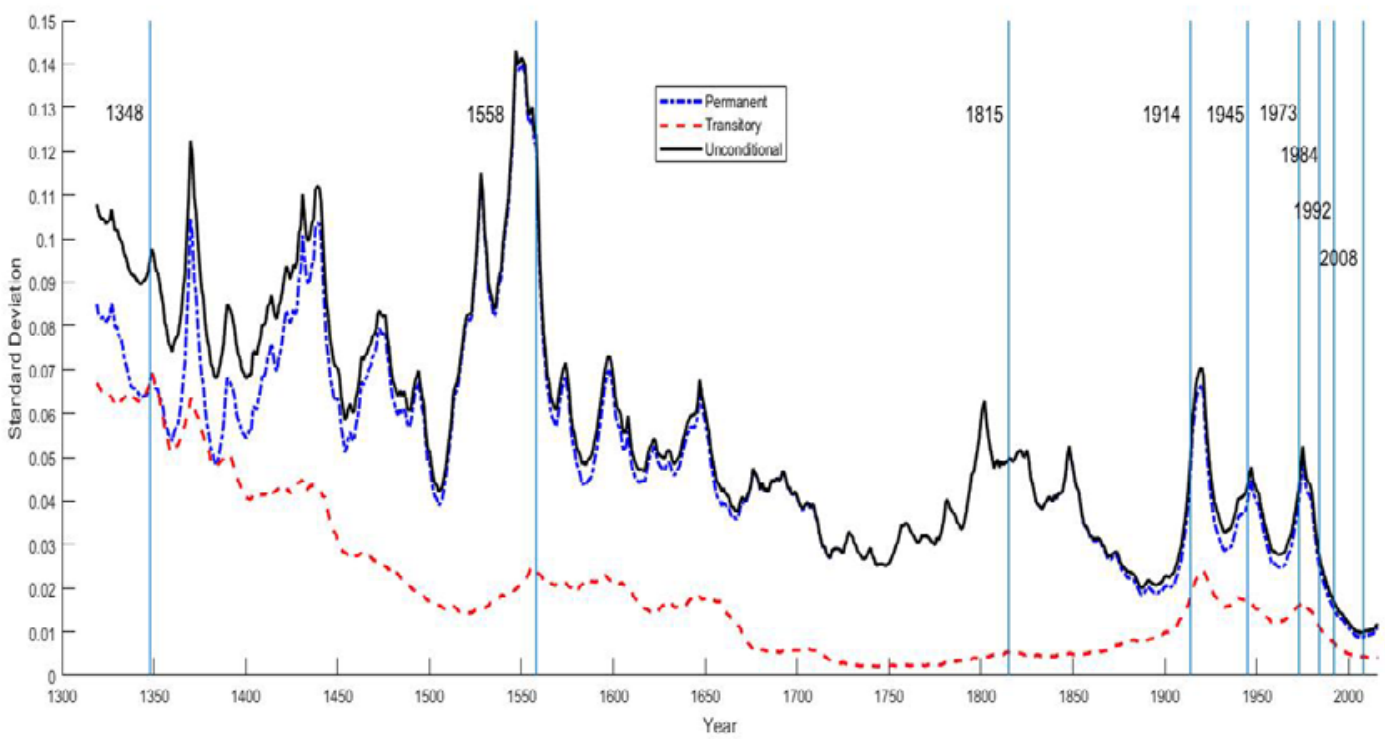

Figure 4: Conditional time-varying standard deviations of output growth 


\begin{tabular}{|c|c|c|c|c|c|c|c|c|c|c|c|c|c|}
\hline \multicolumn{14}{|c|}{ Table 3: Reductions in volatility over different time periods } \\
\hline & & & $1270-1348$ & $1348-1558$ & $1558-1815$ & $1815-1914$ & $1914-1945$ & $1945-1973$ & $1973-1984$ & 1984-1992 & $1992-2008$ & 2008-2016 & Full Sample \\
\hline \multicolumn{14}{|c|}{ Panel A } \\
\hline \multirow{8}{*}{ Output Growth } & \multirow{3}{*}{ Peak } & $\begin{array}{c}\text { Standard } \\
\text { Deviation }\end{array}$ & 0.108 & 0.143 & 0.124 & 0.053 & 0.071 & 0.048 & 0.053 & 0.027 & 0.017 & 0.012 & 0.143 \\
\hline & & Year & 1319 & 1547 & 1558 & 1848 & 1920 & 1947 & 1975 & 1984 & 1992 & 2015 & 1547 \\
\hline & & 16th percentile & 0.092 & 0.119 & 0.101 & 0.045 & 0.063 & 0.042 & 0.046 & 0.024 & 0.015 & 0.010 & [0.119-0.181] \\
\hline & \multirow{3}{*}{ Trough } & $\begin{array}{c}\text { Standard } \\
\text { Deviation }\end{array}$ & 0.089 & 0.042 & 0.025 & 0.020 & 0.033 & 0.028 & 0.027 & 0.017 & 0.010 & 0.010 & 0.009 \\
\hline & & Year & 1343 & 1505 & 1748 & 1887 & 1933 & 1962 & 1984 & 1992 & 2007 & 2008 & 2007 \\
\hline & & 84th percentile & 0.102 & 0.060 & 0.030 & 0.025 & 0.041 & 0.035 & 0.035 & 0.021 & 0.013 & 0.014 & {$[0.009-0.013]$} \\
\hline & \multicolumn{2}{|c|}{ Same period volatility yield } & 0.018 & 0.101 & 0.099 & 0.033 & 0.038 & 0.020 & 0.025 & 0.010 & 0.007 & 0.002 & \\
\hline & \multicolumn{2}{|c|}{ Reductions in volatility (\%) } & --- & $-32.69^{*}$ & $13.33 *$ & $57.63^{*}$ & $-34.41^{*}$ & $32.43^{*}$ & $-10.01 *$ & 47.84 & 38.24 & 31.36 & \\
\hline \multicolumn{14}{|c|}{ Panel B } \\
\hline \multirow{8}{*}{ Inflation } & \multirow{3}{*}{ Peak } & $\begin{array}{l}\text { Standard } \\
\text { Deviation }\end{array}$ & 0.102 & 0.102 & 0.097 & 0.040 & 0.045 & 0.034 & 0.023 & 0.020 & 0.019 & 0.020 & 0.102 \\
\hline & & Year & 1348 & 1349 & 1600 & 1815 & 1921 & 1945 & 1973 & 1984 & 2008 & 2009 & 1349 \\
\hline & & 16th percentile & 0.098 & 0.101 & 0.090 & 0.036 & 0.040 & 0.029 & 0.020 & 0.015 & 0.013 & 0.013 & [0.101-0.109] \\
\hline & \multirow{3}{*}{ Trough } & $\begin{array}{c}\text { Standard } \\
\text { Deviation } \\
\end{array}$ & 0.081 & 0.032 & 0.028 & 0.025 & 0.034 & 0.022 & 0.020 & 0.017 & 0.015 & 0.017 & 0.015 \\
\hline & & Year & 1331 & 1507 & 1767 & 1864 & 1945 & 1962 & 1984 & 1992 & 1998 & 2016 & 1998 \\
\hline & & 84th percentile & 0.090 & 0.036 & 0.032 & 0.030 & 0.041 & 0.028 & 0.025 & 0.022 & 0.021 & 0.025 & {$[0.012-0.021]$} \\
\hline & \multirow{2}{*}{\multicolumn{2}{|c|}{ Same period volatility yield }} & 0.021 & 0.069 & 0.069 & 0.015 & 0.011 & 0.012 & 0.004 & 0.003 & 0.003 & 0.002 & \\
\hline & & & -- & $-0.35^{*}$ & $4.83^{*}$ & $59.22 *$ & $-13.53^{*}$ & $24.05 *$ & $31.52 *$ & 15.88* & $4.13^{*}$ & $-3.60 *$ & \\
\hline
\end{tabular}

Notes: We examine local peaks for increases in volatility and local troughs for reductions. * denotes changes where the upper (84\%) bound of the preceding trough does not overlap with the following lower (16\%) peak. We mark these cases as statistically significant. Negative values in the "changes" row denote increases in the relevant volatility. Brackets in the full sample column denote the $16 \%-84 \%$ posterior credible intervals. 


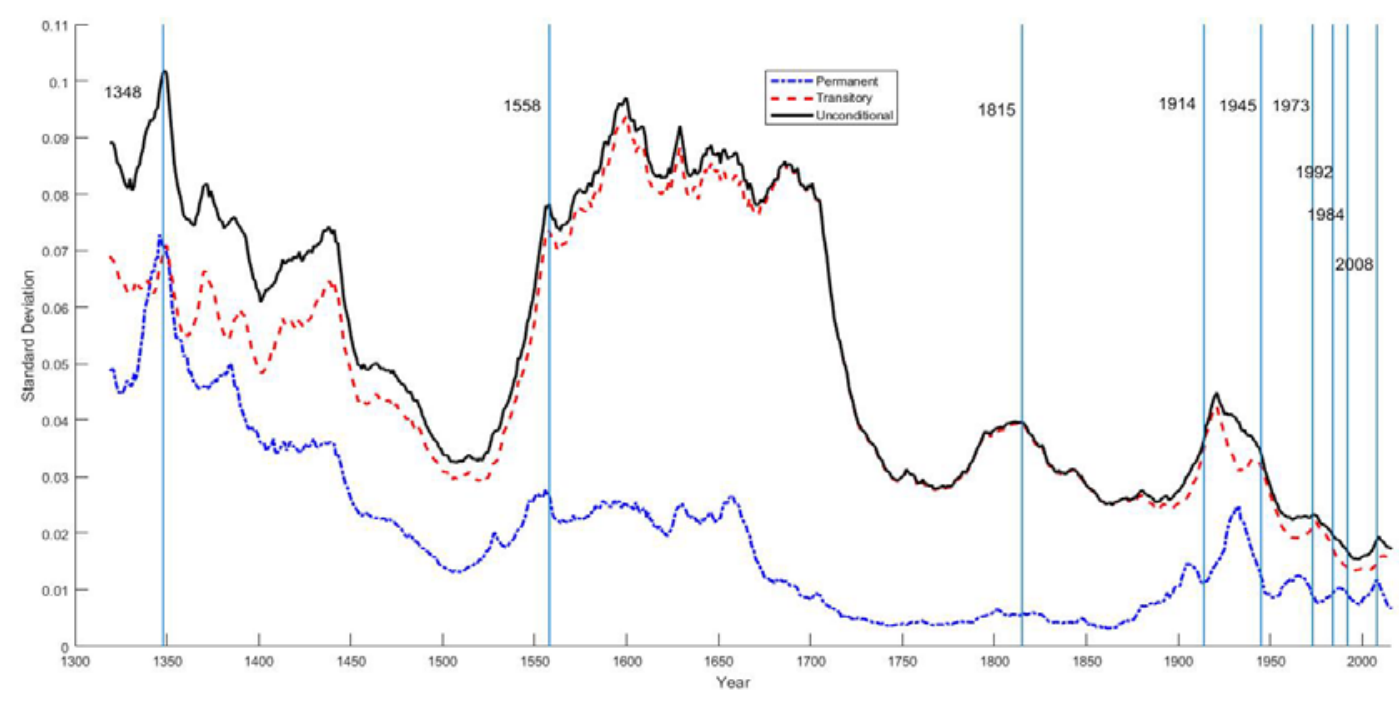

Figure 5: Conditional time-varying standard deviations of inflation.

\subsubsection{TVP-VAR coefficients}

In Figure 6, we report the coefficients for the output growth (first) equation of the TVP-VAR. Given the time-varying nature of our model and the Bayesian estimation that provides the entire posterior distribution of the coefficients, we report both posterior median values and 68\% intervals instead of the typical t-test and F-test statistics reported in time invariant VAR models.
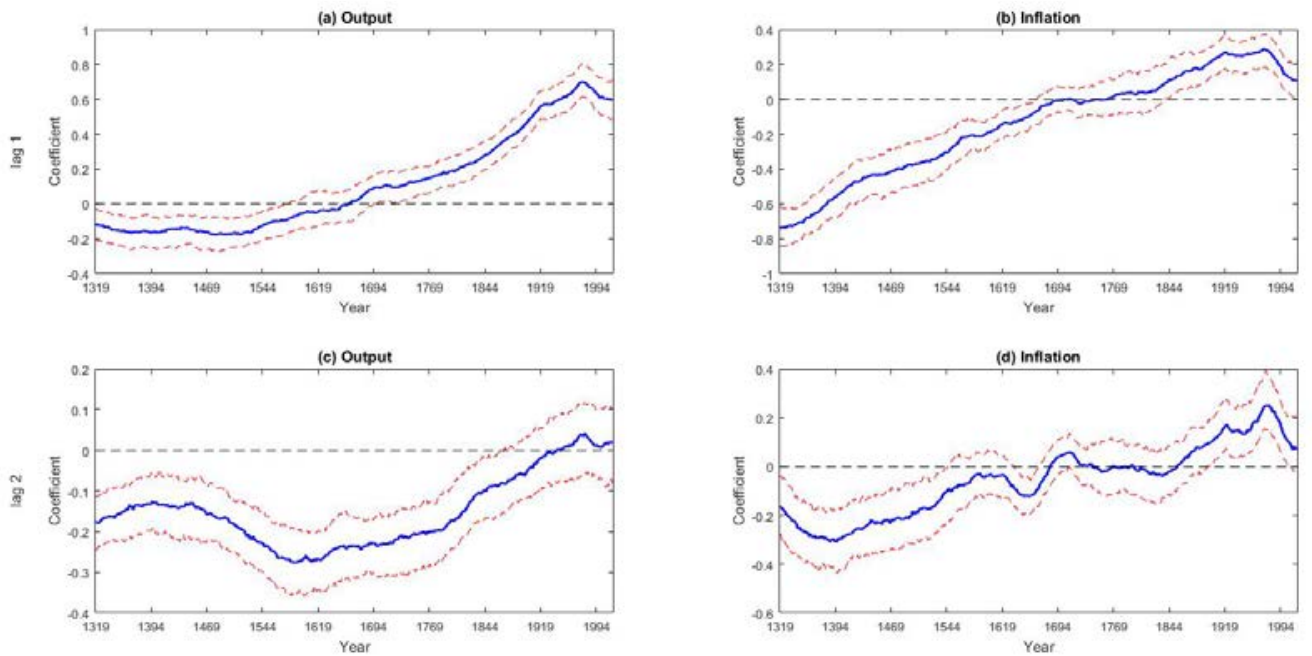

Figure 6: Output (first) equation time-varying coefficients.

As we observe from figure 6, the time-varying coefficients of the first lag for output (subplot a) are mostly statistically significant, while they change their sign 
before and after the 1700 . Before 1700 the output coefficient is negative and small in magnitude (in absolute values), implying a negative relationship between past output values and the future evolution. In the post 1700 period the output coefficient becomes positive and significant reaching to 0.6 in the 1990. Thus, the output growth series is persistent, since past values are significant in the future evolution. A similar pattern is obvious for the inflation coefficient (subplot b) for the first lag. While the past inflation value is negative, large in magnitude (absolute values) and statistically significant for the pre-1700 period, turns positive for the period 1800-1980 and then is smaller but still statistically significant. Regarding the second lag, output coefficients are small in magnitude, negative and statistically significant until the 1800s (subplot c), while the inflation coefficient is mostly statistically insignificant, turns positive with statistical significance after the 1850s and the same drop as the first lag after the 1980s (subplot d). Overall, from the examination of the output equation we observe a significant change in the sign and the magnitude of both the output and the inflation coefficients on future growth rates.
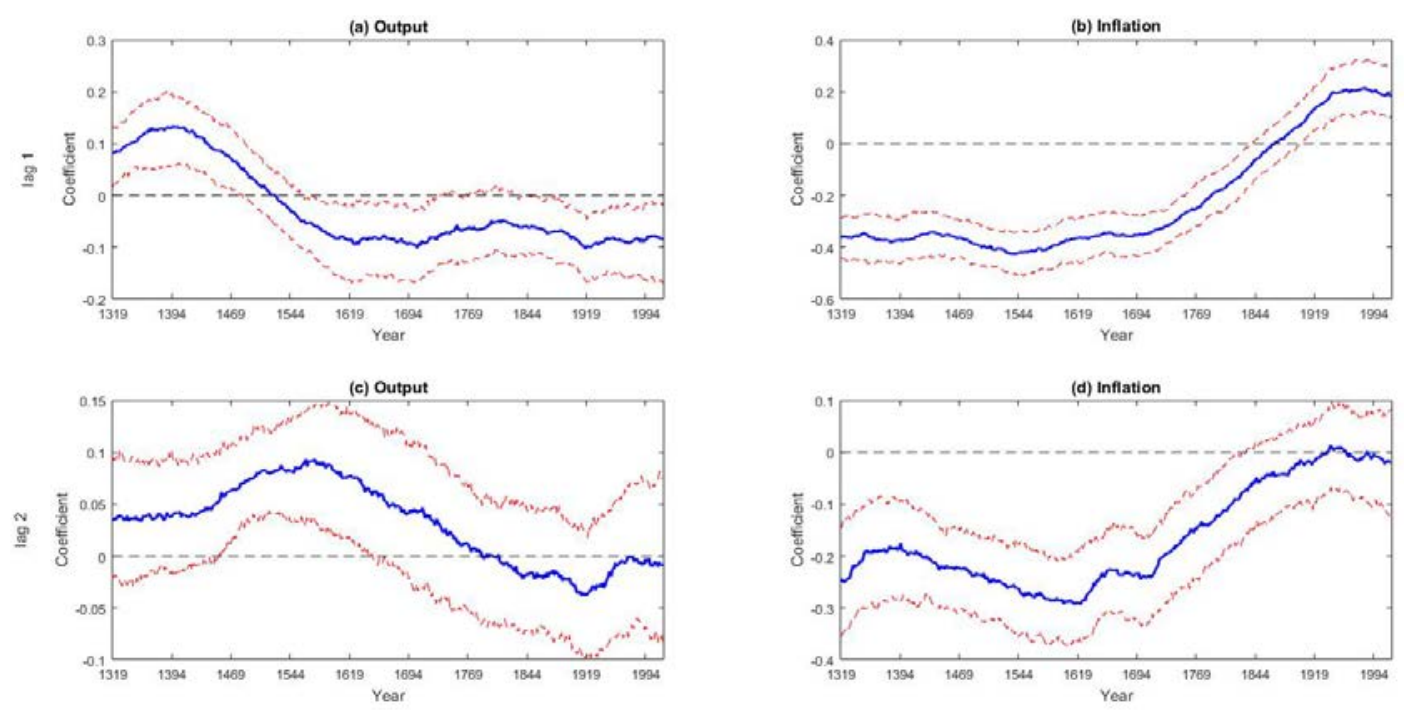

Figure 7: Inflation (second) equation time-varying coefficients.

In figure 7 we depict the time-varying coefficients for the inflation (second) equation of the TVP-VAR model. Examining the coefficient of the first lag for output growth (subplot a) we observe that the coefficient is small in magnitude around 0.1, positive and changes sign keeping the same magnitude (in absolute values) in the post 1500 period. In contrast, the inflation coefficient (subplot b) has a negative, higher value (in absolute prices) in the pre-1800 period and then turns positive and 
statistically significant. Nevertheless, the small positive values of the inflation coefficient do not imply a persistent behaviour of the inflation series. The coefficients for the second lags (subplot c and d) are either small or statistically insignificant, so they do not justify a significant contribution to the evolution of the inflation rate.

\subsubsection{Impulse Response Functions}

While, the examination of the coefficients of the VAR could provide with useful insight to the overall behaviour of the model, it is not adequate to reveal the effect of a shock to the system. Thus, we proceed to an examination of the timevarying responses of the variables to shocks, permanent or transitory.

Given the time-varying nature of our model, we have to add one more axis to the Impulse Response Function (IRF) plot that corresponds to the date of the imposition of the shock. In Figure 8 we report the three-dimensional time-varying impulse responses of our TVP-VAR for both variables.

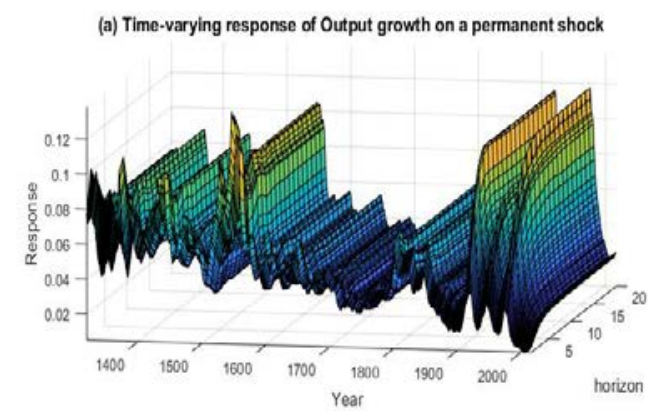

(c) Time-varying response of Output growth on a transitory shock

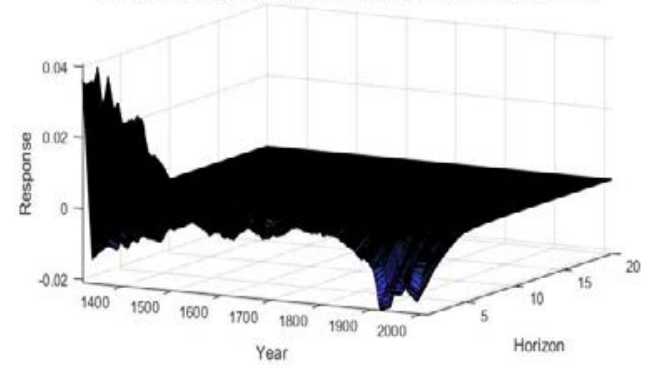

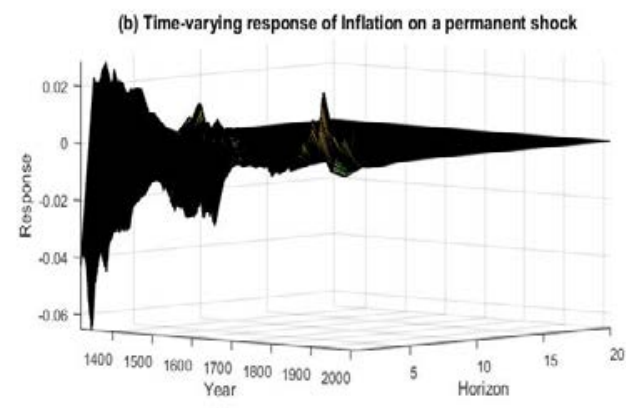

(d) Time-varying response of Inflation on a transitory shock

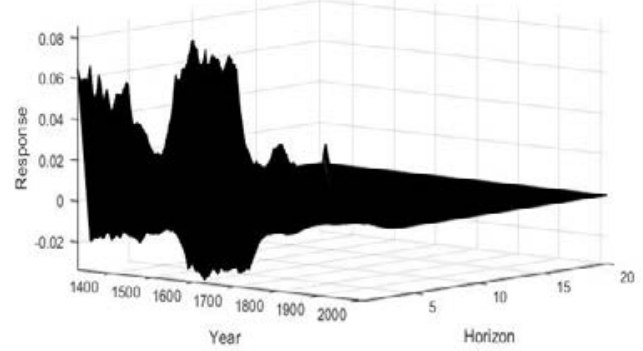

Figure 8: 3D Impulse Response Functions.

As we observe from figure 8a, the response of output growth on a permanent shock is important is larger in magnitude that the one on inflation (figure 8b) and has a larger long-run effect since during certain dates the response reaches up to 20 
periods (years). The larger responses of output growth are in the $20^{\text {th }}$ century and around 1600 . Temporary shocks cause smaller responses in magnitude and short lived for either output growth or inflation. Unfortunately, three-dimensional figures are not useful in drawing statistical inferences, since we cannot plot confidence intervals on them. Thus, in figures 9 to 12, we splice the three-dimensional IRFs into twodimensional graphs and include the $16 \%$ and $84 \%$ credible posterior intervals of the IRFs for various horizons. We plot up to 20 horizons for the output growth response on a permanent shock and depict only up to 10 response horizons for the other shocks and variables, since after that point all responses fade away.
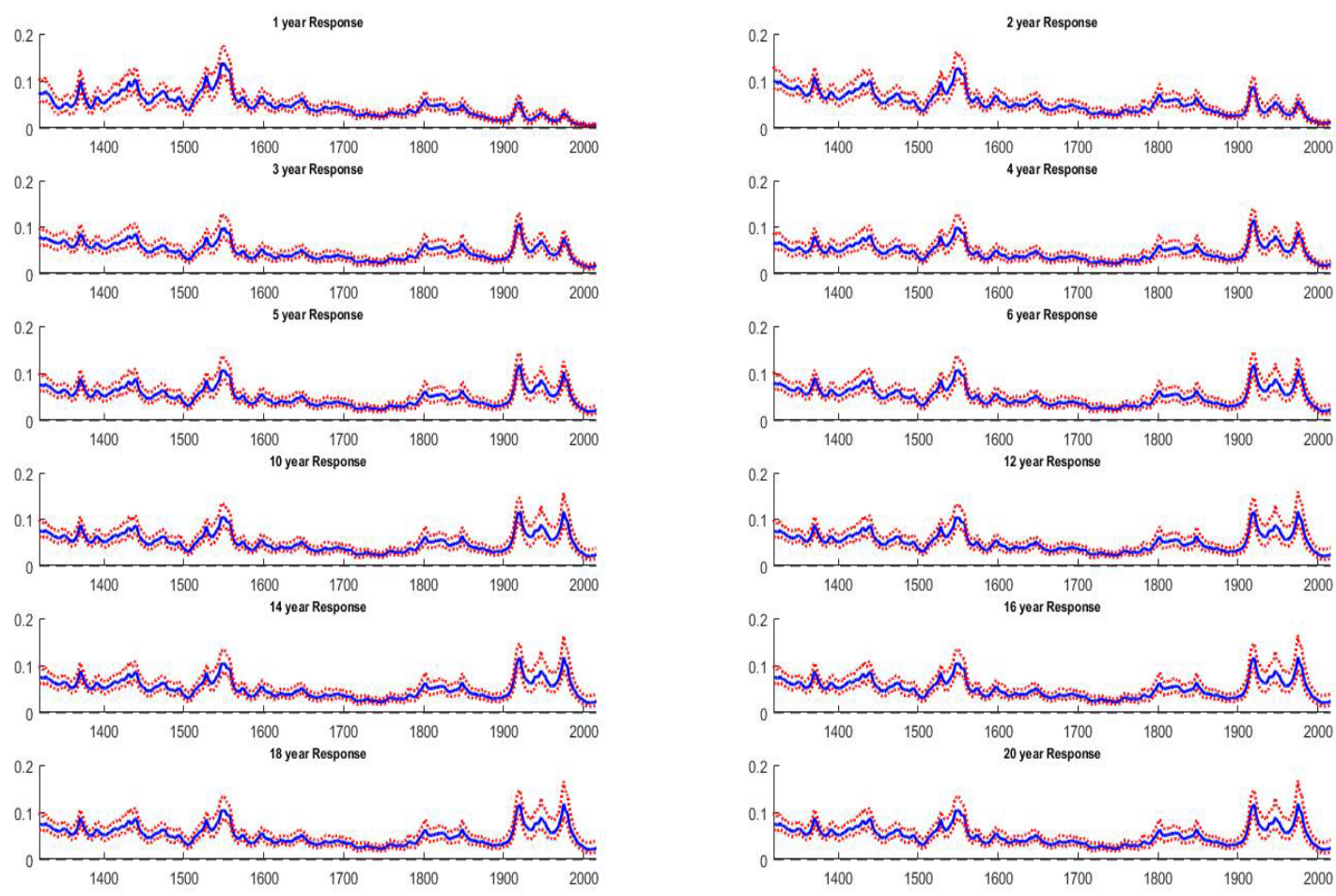

Figure 9: Time varying responses of output growth on a persistent shock.

In figure 9 we present the responses of output growth to the permanent shock in output. As we expect an initially small response gradually increases and reaches its long-run response after the third year response. In all cases the responses are positive and statistically significant. Interestingly, the highest responses in magnitude are marked in the $15^{\text {th }}$ and the $20^{\text {th }}$ century, after a relative irresponsive $16^{\text {th }}$ and $17^{\text {th }}$ century. The Napoleonic wars and the industrial revolution of the $18^{\text {th }}$ century have a significant impact of the long-run response of output growth, something observed for the analysis of the output coefficients. In the $20^{\text {th }}$ century the two world wars, the 
period of high inflation and the great moderation can be main sources of the peaks in the responses in the early and the mid- $20^{\text {th }}$ century. The late $20^{\text {th }}$ century appears to have a significant drop in output growth, which is consistent with the volatility analysis.
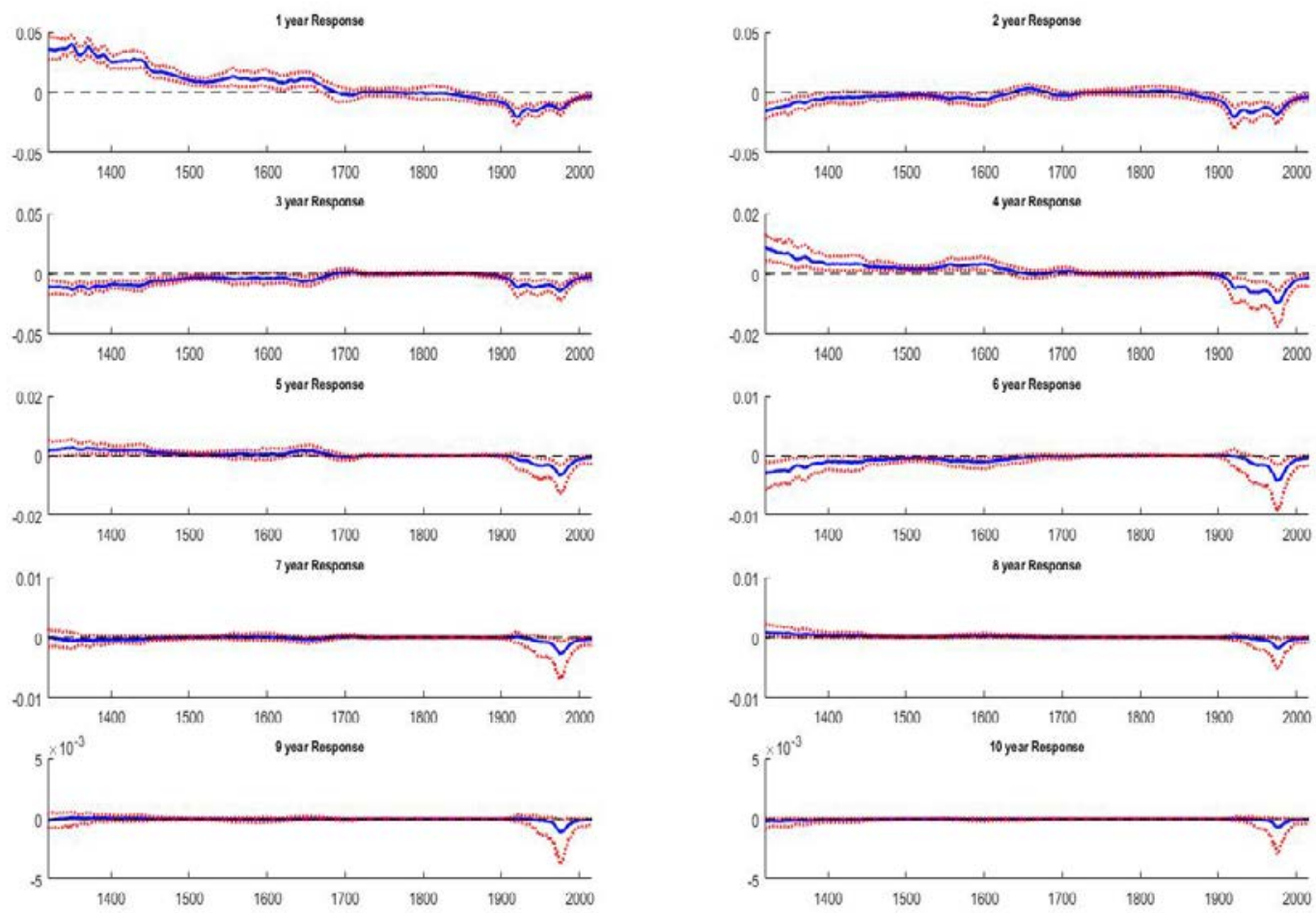

Figure 10: Time varying responses of output growth on a transitory shock.

In figure 10 we depict the long-run response of output growth on a transitory price shock. As expected the response is short-lived, small in magnitude and negative. It is statistically significant up to the 5th-year response only for the post 1900 period because of the two world wars the cost of inflation in the output growth. The responses of inflation on a temporary output shock (figure 11) is negative, extremely short-lived for a long-run response up to 2 years and for the pre 1500 period. In the long-run and for certain sub-periods it turns positive but overall the response is only episodically different from zero with statistical significance. In contrast, the response in price level on a transitory shock (figure 12) is positive, larger in magnitude and statistically significant for the first year after the imposition of the shock, turns negative and smaller in the $2^{\text {nd }}$ and $3^{\text {rd }}$ year response and then positive only for the $16^{\text {th }}$ and $17^{\text {th }}$ century for the fourth year response. From that point on all response fades away. The positive values of the short-term responses follow in general the 
transitory volatility path and can be interpreted as short-term shocks that have no impact on output and affect temporarily the nominal output.
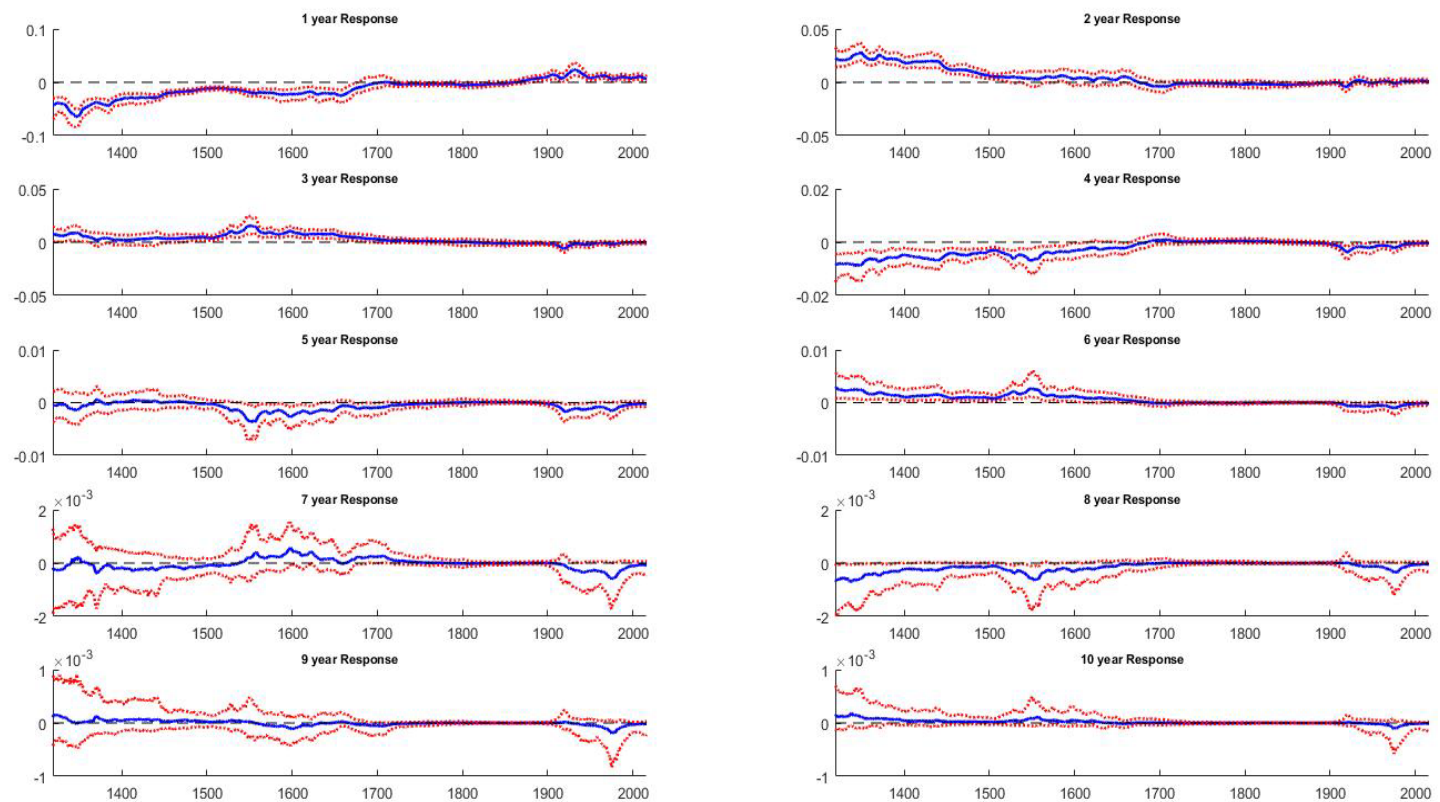

Figure 11: Time varying responses of inflation on a permanent shock.
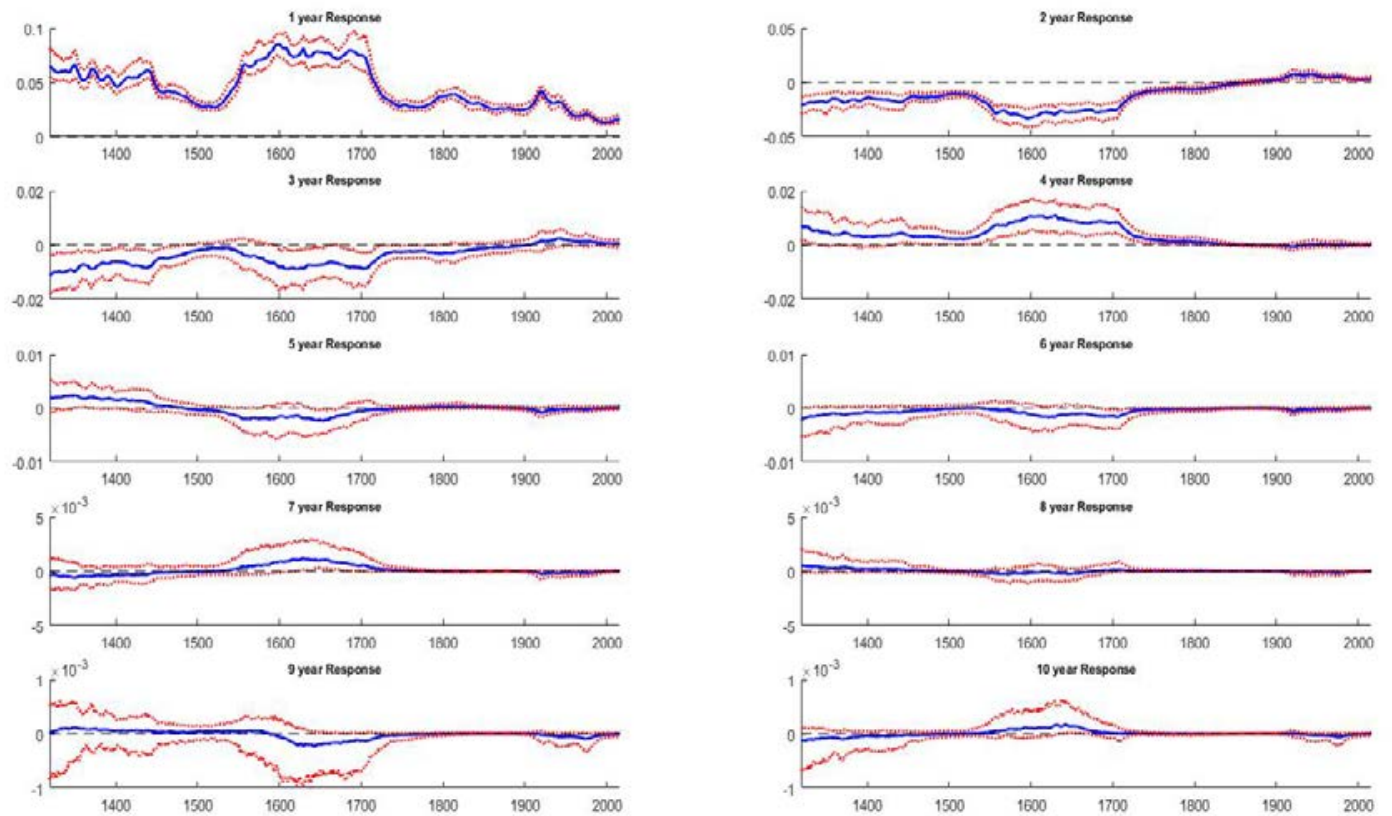

Figure 12: Time varying responses of inflation on a transitory shock.

From the analysis of the time-varying responses of output growth and inflation of permanent and transitory shocks on output growth we gain useful insights on the 
evolution of output and inflation over time. Most of the output responses on permanent and transitory shocks follow the notion of aggregate supply and aggregate demand shocks in the economy, with the exception of transitory price shocks $\left(16^{\text {th }}\right.$ and $17^{\text {th }}$ century). We do not find that the $15^{\text {th }}$ century was period of exceptional growth for England as stated by Broadberry and Fouquet (2015), while the $20^{\text {th }}$ century has also exhibited positive and high in magnitude peaks in output growth responses that can be compared with the tumultuous period in the early 1500 . This finding is interesting since it corroborates with the business cycle literature that supports the existence of high macroeconomic volatility during periods of increased macroeconomic uncertainty.
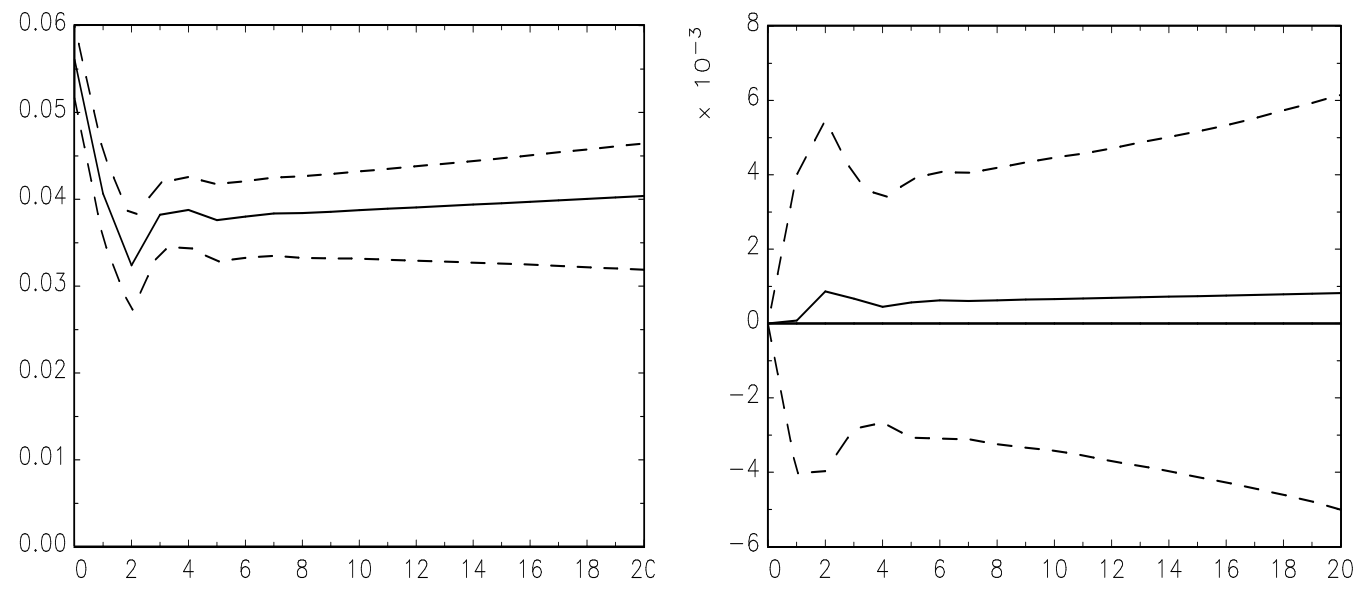

Figure 13: Time invariant output growth responses based on a VECM with constant parameters over time. Responses on a permanent output growth shock are reported on the left figure and on a transitory shock on the right. The 95\% confidence intervals depicted in dashed lines and are computed based on 10000 bootstrap repetitions.
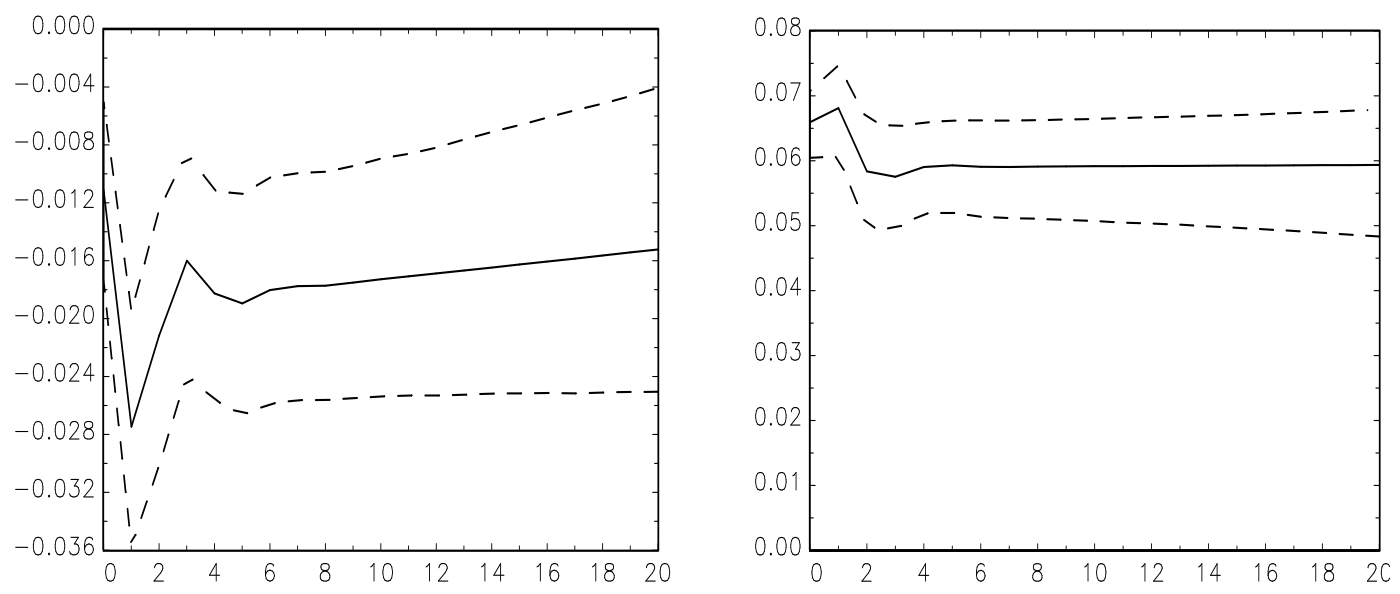
Figure 14: Time invariant inflation responses based on a VECM with constant parameters over time. Responses on a permanent output growth shock are reported on the left figure and on a transitory shock on the right. The 95\% confidence intervals depicted in dashed lines and are computed based on 10000 bootstrap repetitions.

In figures 13 and 14 we show the long-run impact responses of output growth and inflation to a permanent and a transitory shock for a SVECM with constant parameters over time. In order to be consisted with our previous analysis we impose the same BQ-type long-run restrictions on the effects of the shocks. The details of the SVECM are reported in the Appendix. As we observe from figure 13, a permanent shock has a positive and significant response of output-growth that reaches its longrun response almost immediately after 3 periods and remains constant ever since. The response of output growth on a transitory shock is statistically insignificant. The responses of inflation (figure 14) on a permanent shock are positive but small in magnitude, while the sigh reverses for a transitory shock. Overall, while the time invariant analysis corroborates to theory fails to provide the perspective of changes in the behaviour of output growth and inflation conditioned on the macroeconomic and political conditions that prevail at the time of the imposition of the shock.

\section{Discussion and Policy}

The examination of the unconditional volatilities of figure 3 raises some questions: why did ouput volatility undergo such a big reduction during the period 1550-1800 and after 1984? Why did inflation volatility rise after the 1550 ? In trying to account for large volatility changes in output and inflation volatilities economists focus on two potential sources: structural changes or policy reactions. When they fail to pinpoint either of them, then the "good luck" scenario comes into place. According to the stylized fact of a "good luck" scenario, small exogenous shocks in the economy cause a decrease in volatility without a significant policy or structural change effect (Keating and Valcarcel, 2017). In other words, the permanent shocks to economy have a lukewarm effect and most of the observed impulse responses should be attributed to transitory sources.

Policy changes that coincide with significant changes in the volatility of output and growth are indeed obvious in our analysis. With the commencement of the Tudors' reign in 1558, we observe a significant drop in output volatility in 
comparison to the previous periods, that clearly underlines a change in policy. In fact, as we observe from figure 4, output volatility conditioned on permanent shocks adhere very closely to the unconditional output growth volatility, while the effect of transitory shocks are reduced. This consistency in the economic policy continues to drive the effects from price shocks down for the entire 1550-1914 period, after the end of the Civil War at 1668 and the way towards monarchy. During 1750s, we observe the lowest value of output volatility conditioned on the transitory price shocks. The increase in the unconditional inflation volatility could be a sign of policies dedicated to output expansion regardless of the increases in the price level. This effect could also be attributed to the increased income from trade. Nevertheless, all these are assumptions that cannot be tested formally within our TVP-VAR model and require a Dynamic Stochastic General Equilibrium (DSGE) approach.

Local peaks in the unconditional output growth volatility at the end of the WWI and WWII could be attributed to structural changes in the economy, given that a large part of the economy's assets were dedicated to supporting the wars and a large part of the labour force and capital was lost. Another policy change that occurred near the end of WWII is the establishment of the Bretton Woods system that fixed the exchange rates of other countries to the dollar and tied the dollar to gold. Some believed Bretton Woods would return economies to a level of stability not seen since the Classical Gold Standard - the period from 1880 to 1913. Volatilities for inflation and output growth fall dramatically during the Bretton Woods regime, and both volatilities were smaller, frequently much smaller, during the Classical Gold Standard than at any other time before 1945. This finding is also corroborated by the fact that in the dissolution of the Bretton Wood system in 1973, we observe a steep increase in both volatilities. After 1992 (period of the Great Moderation), both output and inflation volatilities fall dramatically as a result of inflation reduction and output expansion policies by the Bank of England. Nevertheless, both the Bretton woods and the post-1992 period are very small in comparison to the $1550-1800$ prolonged period of low output volatilities.

In contrast, the large increases in the non-technological (transitory shocks) during certain periods of low volatility (around 1668) and their obvious decline when output volatility remained low, provides mixed results about the effect of transitory 
shocks on the "good luck" hypothesis. The structural interpretation of the shocks allows us to argue that the recent post-1992 decline in volatility cannot be explicitly interpreted by neither the policy/structural changes approach, nor the exogenous effect on volatility. We believe that the phenomenon is more complex and is based on all sources of volatility.

Based the aforementioned analysis, we believe that a policy targeted on reducing either inflation or output volatility should follow a holistic approach; where the central bank needs to adopt policy measures and examine for potential exogenous sources of volatility and the existence of structural changes. Starting from the latter, a structural change in the way that the economy is organised and produces usually takes a long time to happen and to be identified in general. Thus, the effect on volatility would be captured by a technology shock on output and inflation, adhering better to the permanent shock of our structural model. Exogenous responses would follow the transitory shocks. With that in mind, a policy maker could determine the current stance of the economy and the main factors that contribute to the volatility of output and inflation. Given that permanent and transitory shocks act as aggregate supply and demand, the policy authority could use the ideal mixture of policy measures to either boost the supply or the demand side of the economy. However, given the importance of the shocks are time-varying, policy makers need to use a time varying approach and cannot rely on fixed coefficient models, as the latter will only provide an overall picture and how the importance of the shocks has evolved over time, and also where they stand at a specific point in time. Policy-making based on constant parameter model would likely lead to incorrect inferences (Bataa et al., 2015) ${ }^{5}$, and fail to account for the variability in the relationships over time, which along with nonlinearity, is captured through a time-varying framework.

So in summary, in terms of policy-making, we can indicate the following points: (a) Policy, and in particular monetary policy, should be targeted to reducing both output and inflation volatility, and not one particular volatility, by identifying the sources of the same to understand what is driving the movements of these volatility.

\footnotetext{
${ }^{5}$ Our analysis is somewhat related to that of Bataa et al., (2015), who used a constant parameter VAR model to analyze the relationship between interest rate, output growth and inflation over the historical period of 1820-2014. They however, conducted sub-sample analysis by identifying structural breaks instead of the time-varying approach used in our case, and also looked at a much shorter period than ours. In addition, Bataa et al., (2015) also did not analyze the impact of shocks on volatility.
} 
This in turn, would require a micro-founded structural approach and require the policy-maker to go beyond the structural VAR approach used in this paper. In this regard, a Bayesian DSGE model should be of help. Clearly then, the policymakers loss function should give importance to both output and inflation volatilities, and; (b) Given that we show that the nature of the impact of shocks on the economy varies over time, i.e., the relationship is nonlinear, and in other words nonlinear model are required, i.e., specifically speaking nonlinear DSGE type models with stochastic volatility. This will allow the policymaker to better identify the drivers of volatility, and then devise appropriate responses to circumvent volatility in output and inflation, thus reduce uncertainty in the decision-making process of the economic agents.

\section{Conclusions}

In this paper, we address the issue of recurring patterns in the economic history of the U.K. based on a TVP-VAR model with Bayesian estimation and BQtype long-run assumption in the identification of the responses based on a permanent and a transitory shock. In doing so we examine output growth and inflation for the period 1270-2016, i.e., covering the entire U.K. economic history. Our empirical results reveal that most of the output volatility could be attributed to aggregate supply shocks and is gathered in the two sides of our sample; the pre-1600 period and the $20^{\text {th }}$ century. This recurring pattern in output volatility signals significant changes in the U.K. economy with much of the variation stemming from the intense political events of these periods. Most of the volatility appears around significant economic or political events, such as the dissolution of the Bretton Woods system or the two World Wars. These findings are also corroborated by the examination of the long-run responses. Given that the Blanchard and Quah (1989) analysis fails to provide structural description of the economy, a future path of research could be the analysis based on a Bayesian DSGE model on our long-span data.

\section{References}

Bai J. and Perron P. (2003) Computation and analysis of multiple structural change models. Journal of Applied Econometrics, 18 (1), 1-22.

Barnett A., Mumtaz H., and Theodoridis K. (2014) Forecasting UK GDP growth and inflation under structural change. A comparison of models with time-varying parameters. International Journal of Forecasting, 30, 129-143. 
Bataa, E., Vivian, A., and Wohar, M.E. (2015). Changes in the relationship between short-term interest rate, inflation and growth: Evidence from the UK, 1820-2014. MPRA Paper No. 72422.

Benatti L. (2008). The "Great Moderation" in the United Kingdom. Journal of Money Credit and Banking, 40(1), 121-147.

Bierens, H. J. and Martins, L.F. (2010) Time Varying Cointegration, Econometric Theory, 26, 1453-1490.

Blanchard, O.J. and Quah, D. (1989). The dynamic effects of aggregate demand and supply disturbances. American Economic Review, 79 (4), 655-673.

Bordo, M.D. (1993) “The Gold Standard, Bretton Woods and Other Monetary Regimes: A Historical Appraisal,” in M.T. Belongia ed. Dimensions of Monetary Policy: Essays in Honor of Anatol B. Balbach, Federal Reserve Bank of St. Louis, 123-191.

Broadberry S. and Fouquet R. (2015). Seven Centuries of European Economic Growth and Decline. Journal of Economic Perspectives, 29, 227-244.

Bullard, J., and Keating, J.W. (1995). The long-run relationship between inflation and output in postwar economies, Journal of Monetary Economics, 36, 477-496

Canova F. and Gambetti, L. (2010). Do expectations matter? The great moderation revisited. American Economic Journal: Macroeconomics, 2 (3), 183-205.

Clark G. (2006) Farm Wages, Population and Economic Growth, England, 12091869. Economic History Review, 60(1), 97-134.

Clark G. (2004) The price history of English agriculture, 1209-1914. Research in Economic History, 22, 41-120.

Cogley T., Primiceri E. and Sargent T. (2010) Inflation-Gap persistence in the U.S. American Economic Journal: Macroeconomics, 2 (1), 46-69.

Cogley, T. and Sargent, T. (2005). Drifts and volatilities: monetary policies and outcomes in the post WWII US. Review of Economic Dynamics, 8 (2), 262-302.

Dickey D, Fuller W. 1981. Likelihood ratio statistics for autoregressive time series with a unit root. Econometrica 49: 1057-1072.

Dickey, D. and Fuller, W. (1981). Likelihood ratio statistics for autoregressive time series with a unit root. Econometrica, 49, 1057-1072.

Enders W, Lee J (2012) A unit root test using a Fourier series to approximate smooth breaks. Oxford Bulletin of Economics and Statistics, 74(4), 574-599.

Johansen, Søren (1991). "Estimation and Hypothesis Testing of Cointegration Vectors in Gaussian Vector Autoregressive Models". Econometrica. 59 (6): 1551-1580.

Karras, G. (1994) "Aggregate Demand and Supply Shocks in Europe: 1860-1987," The Journal of European Economic History 22:79-98.

Keating J and Valcarcel V. (2017) What's so great about the Great Moderation, Journal of Macroeconomics, 51, 115-142. 
Kwiatkowski D, Phillips PCB, Schmidt P, Shin Y. 1992. Testing the null hypothesis of stationarity against the alternative of a unit root. Journal of Econometrics 54: 159-178.

Liu J, Wu S, Zidek JV (1997) On segmented multivariate regression. Statistica Sinica 7, 497-525.

Ng, S. and Perron, P. (2001). Lag length selection and the construction of unit root tests with good size and power. Econometrica, 69, 1519-1554.

Phillips PCB, Perron P. 1988. Testing for a unit root in time series regression. Biometrika 75: 335-346.

Phillips, P. and Perron, P. (1988). Testing for a unit root in time series regression. Biometrika, 75, 335-346.

Rapach, D.E. (2003). International Evidence on the Long-Run Effects of Inflation. Journal of Money, Credit, and Banking, 35(1), 23-48.

Reinhart, C.-M. and Rogoff K. (2009). This Time Is Different: Eight Centuries of Financial Folly. Princeton, New Jersey: Princeton University. 